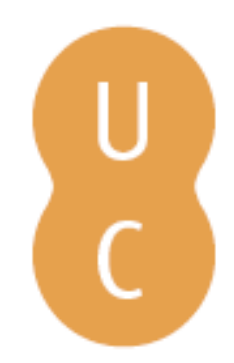

\title{
pommalina
}

\section{Geotectónica e granitos portugueses: o pioneirismo dos anos $\mathbf{4 0}$}

Autor(es): $\quad$ Andrade, António Soares de; Pinto, Manuel Serrano

Publicado por: Imprensa da Universidade de Coimbra; Laboratório de Radioactividade Natural da Universidade de Coimbra

URL

persistente:

URI:http://hdl.handle.net/10316.2/36293

DOI:

DOI:http://dx.doi.org/10.14195/978-989-26-1009-2_6

Accessed : $\quad$ 26-Apr-2023 16:31:39

A navegação consulta e descarregamento dos títulos inseridos nas Bibliotecas Digitais UC Digitalis, UC Pombalina e UC Impactum, pressupõem a aceitação plena e sem reservas dos Termos e Condições de Uso destas Bibliotecas Digitais, disponíveis em https://digitalis.uc.pt/pt-pt/termos.

Conforme exposto nos referidos Termos e Condições de Uso, o descarregamento de títulos de acesso restrito requer uma licença válida de autorização devendo o utilizador aceder ao(s) documento(s) a partir de um endereço de IP da instituição detentora da supramencionada licença.

Ao utilizador é apenas permitido o descarregamento para uso pessoal, pelo que o emprego do(s) título(s) descarregado(s) para outro fim, designadamente comercial, carece de autorização do respetivo autor ou editor da obra.

Na medida em que todas as obras da UC Digitalis se encontram protegidas pelo Código do Direito de Autor e Direitos Conexos e demais legislação aplicável, toda a cópia, parcial ou total, deste documento, nos casos em que é legalmente admitida, deverá conter ou fazer-se acompanhar por este aviso.

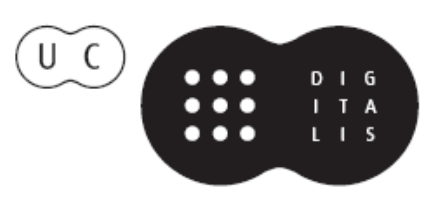




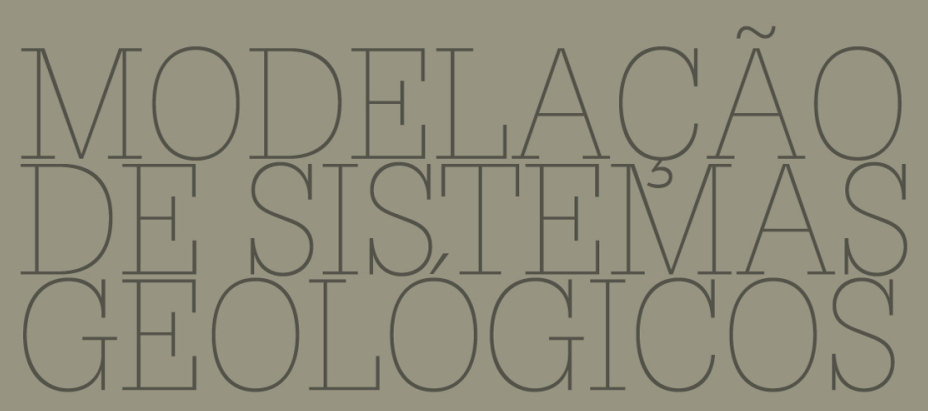

Homenagem ao Professor Doutor Manuel Maria Godinho

L.J.P.F. Neves, A.J.S.C. Pereira,

C.S.R. Gomes, L.C.G. Pereira,

A.O. TAVARES

IMPRENSA DA UNIVERSIDADE DE COIMBRA

CoImBra University Press 


\title{
MODELAÇÃO \\ DE SISTEMAS \\ GEOLÓGICOS
}

Homenagem ao Professor Manuel Maria Godinho

\section{Geotectónica e granitos portugueses: 0 pioneirismo dos anos 40}

\author{
António Soares de Andrade ${ }^{1}$; Manuel Serrano Pinto ${ }^{2}$ \\ ${ }^{1}$ Departamento de Geociências (Geobiotec), Universidade de Aveiro, PORTUGAL, asandrade@ua.pt \\ ${ }^{2}$ Departamento de Geociências (Geobiotec), Universidade de Aveiro, PORTUGAL, mspinto@ua.pt
}

Palavras-chave: Geologia, Geotectónica, Península Ibérica, Anos 40

\section{Resumo}

A década de 1940 marca o início de uma renovação da Geologia portuguesa, graças sobretudo ao entusiasmo de dois jovens geólogos da Universidade do Porto, Carlos Teixeira e Cotelo Neiva, e à experiência do seu Mestre comum, J. Carríngton da Costa. O posicionamento geológico dos granitos do centro e norte de Portugal é então objecto de uma interessante controvérsia entre o petrólogo Cotelo Neiva e o estratígrafo Carlos Teixeira; mas a falta de uma detalhada cartografia geológica pouco mais permite do que legítimas dúvidas e perspicazes conjecturas. É também na década de 40 que, na vizinha Espanha, e já com bom suporte cartográfico, os alemães W. Carlé e P. Schmidt-Thomé conseguem seriar cronologicamente 3 grupos de granitos hercínicos: novos, velhos e mais velhos. Mas são diferentes os critérios que utilizam; de modo que aqueles nomes não designam exactamente as mesmas coisas. É ainda na década de 40 que surgem, de modo independente, dois notáveis ensaios geotectónicos, um mais fixista ("hercinotípico") e bem conhecido (F. Lotze), o outro mais mobilista ("alpinotípico") e ainda hoje praticamente desconhecido (A. Schneider). Ambos são pioneiros e permitem, cada um à sua maneira, entender melhor a lógica dos granitos na orogenia varisca da Península Ibérica.

Key-words: Geology, Geotectonics, Iberia, Pioneering forties

\begin{abstract}
Knowledge of the geology of Portugal received in the 1940s a strong impulse of renovation due mainly to the enthusiasm of two young geologists, Carlos Teixeira and Cotelo Neiva, both working at the Oporto University under the guidance of J. Carrington da Costa. The geological age of the granites occurring in northern and central Portugal was the theme of an interesting controversy between Neiva, a petrologist, and Teixeira, a stratigrapher. Unfortunately the lack of detailed geological maps of such areas did not allow them to do much more than presenting reasonable doubts and cute conjectures. In the same decade but in Spain the German geologists W. Carlé and P. Schmidt-Thomé, based on good mapping, succeeded in establishing a chronological sequence of three groups of Hercynian granites: new, old and older ones. But for that effect they used different criteria and so such names do not mean the same thing. Still in the 1940s two notable geotectonic essays were
\end{abstract}


published, one by the well known F. Lotze and the other by the practically unknown (still today) A. Schneider, the former of the fixist type (hercynotype) and the latter of the mobilist type (alpinotype). Both are pioneering studies that, each in its own way, allowed for a better understanding of the role of granites during the Hercynian orogeny in the Iberian Peninsula.

\section{Introdução}

O Maciço Hespérico é, como se sabe, o mais extenso dos diversos afloramentos da cadeia hercínica ou varisca da Europa (por uma questão de comodidade, os termos varisco e hercínico serão aqui considerados sinónimos). Mas ele é também aquele em que mais extensamente afloram rochas graníticas (s.1.). Por isso não deixa de surpreender a pouca atenção que, até à década de 40 (1940), aquelas rochas mereceram da parte dos investigadores portugueses: ainda em 1922 o Prof. Ernest Fleury se via obrigado a declarar, num pequeno texto muito didáctico, que, "contrariamente a uma opinião muito espalhada, os granitos não são rochas vulcânicas nem as formações mais antigas. São rochas que se introduziram e solidificaram através dos terrenos do Primário médio e base do Superior e, se eles afloram, foi a erosão que os poz a nú, e, por consequência a Meseta perdeu uma grande parte da sua cobertura" (Fleury, 1922a, p. 10).

A década de 40 marca o início de uma renovação da Geologia portuguesa; representam-na sobretudo os jovens Carlos Teixeira e Cotelo Neiva que, com o seu Mestre Carríngton da Costa, fundam em 1940, na cidade do Porto, a Sociedade Geológica de Portugal (Neiva, 2009). Cotelo Neiva inicia então uma carreira dedicada em grande parte ao estudo petrológico e metalogénico dos granitos portugueses (nomeadamente Minho e Beiras). Carlos Teixeira e Cotelo Neiva viriam mais tarde a liderar, com o sucesso que é de todos conhecido, as escolas de Lisboa e de Coimbra, respectivamente.

É também na década de 40 que os alemães W. Carlé e P. SchmidtThomé elaboram, com detalhado apoio cartográfico, uma seriação temporal "moderna" dos granitos aflorantes na Galiza e em Castela-Estremadura, respectivamente.

É ainda na década de 40 que vão surgir, de modo independente, dois ensaios geotectónicos fundamentais, onde a problemática dos granitos hercínicos do Maciço Hespérico ocupa um lugar relevante e adquire aspectos de originalidade. Os autores são ambos alemães; mas se um (Franz Lotze) era então já bastante prestigiado, o outro (André Schneider) ainda 
hoje permanece um ilustre desconhecido.

Muita desta actividade é hoje mal conhecida. Vale a pena recordá-la.

\section{Cotelo Neiva, Carlos Teixeira e os granitos portugueses}

O estudo sistemático dos granitos portugueses teve pois início nos anos 40, com os primeiros trabalhos de Cotelo Neiva. Importa contextualizá-los.

Estes trabalhos são feitos "em voo rasante", isto é, as rochas graníticas são analisadas sistematicamente, afloramento por afloramento, em termos petrográficos e, sempre que possível, geoquímicos e metalogénicos, onde é perceptível a influência de Paul Niggli. Era um tempo de inventariação, obviamente com trabalho de campo, mas sobretudo de laboratório. E, à boa maneira indutiva, sem grande necessidade de um quadro geotectónico integrador e guia das observações. $\mathrm{O}$ que explica a ausência de cartas geológicas detalhadas (ex.: 1/50000) integrando aquelas descrições. Refira-se, a propósito, que, embora a Geologia seja uma ciência muito "visual", era de certo modo uma tradição portuguesa que as publicações geológicas apresentassem pouca informação cartográfica de apoio: vejam-se, por exemplo, as teses de doutoramento de Cotelo Neiva e de Carlos Teixeira e sobretudo de Carríngton da Costa. A mais notável excepção é, como se sabe, o "luso-suiço" Paul Choffat.

A ênfase dada por Cotelo Neiva aos granitos do centro e norte do país ter-se-á devido a factores quer "logísticos" (nascimento e infância em S. Mamede de Riba Tua, estudos superiores na Universidade do Porto) quer "opcionais" (atracção pelo então valiosíssimo volfrâmio, como bom exemplo da "Geologia ao serviço do Homem"). Mas aquela ênfase não impedia um olhar atento sobre as intrusões, mais diversificadas, do Alto Alentejo, pontual mas sistematicamente descritas 3 décadas atrás por outro eminente petrógrafo, Vicente de Souza-Brandão. Cotelo Neiva nunca deixaria, aliás, de sublinhar o contraste entre os tardios granitos do Minho e Beiras e os precoces dioritos, tonalitos e gabros do Alto Alentejo.

A idade dos granitos do Minho e Beiras alimentou, nos anos 40 (e subsequentes), uma proveitosa controvérsia entre o petrólogo Cotelo Neiva e o estratígrafo Carlos Teixeira:

Para Cotelo Neiva, 1) dada "a inexistência de calhaus de granito nos conglomerados westfalianos das proximidades de São-Félix e de Moinhoda-Ordem, quer nos estefanianos que dos arredores do Pôrto se estendem até próximo de Queiriga e nos conglomerados autunianos do Buçaco; a existência de calhaus rolados de granito nos afloramentos triássicos de Coimbra e do Buçaco; a existência de detritos de pegmatites graniticas no 
Triássico desta última região; a metamorfização do Estefaniano médio pelos granitos, reconhecivel na pequena mancha de São-Miguel-o-Anjo, próximo do Porto, na região do Gafanhão (Castro Daire), e também bem visível próximo das povoações de Nogueira e Côta (Viseu); e o idêntico quimismo de variados tipos de granitos", 2) estando, "na generalidade, comprovado que, após ter sido atingido, num movimento orogénico, o período de mais forte compressão, formativo de intenso dobramento, ocorreram abundantes intrusões graníticas" e 3) "sendo a fase saálica (...) a mais importante dos movimentos hercínicos no nosso País (...), é muito natural que, sendo os granitos posteriores ao Estefaniano médio e antetriássicos, estejam relacionados com os movimentos orogénicos paroxismais daquela fase "(...) pelo que "dataria muito provavelmente do Pérmico a intrusão granítica das Beiras e do Norte de Portugal" (Neiva, 1944b, p. 3-4).

Carlos Teixeira adopta uma posição mais matizada. Aceitando embora que "o extenso afloramento de granito porfiróide das Beiras e do Minho e os afloramentos da mesma rocha dispersos por Trás-os-Montes, correspondem, sem dúvida, à mesma intrusão" (Teixeira, 1954, p. 35), defende que a sua idade seria carbónica e não pérmica, uma vez que a fase astúrica seria talvez a mais importante: "é o movimento astúrico que parece apresentar maior generalidade, atingir mais extensa área. É porém com a fase saálica que o Dr. Cotelo Neiva julga estar relacionada (...) a intrusão granítica das Beiras." (Teixeira, 1944, p. 120). Teixeira levanta, contudo, uma questão interessante: "De um modo geral, pode dizer-se que a maior parte dos granitos intrusivos são post-tectónicos em relação aos movimentos principais. Contudo, em certos casos, observam-se granitos anteriores à orogénese principal, embora posteriores a uma fase mais antiga" (Teixeira, 1945, p. 120). O que o conduza a uma conclusão lógica mas, na falta de uma cartografia detalhada, hipotética: "Isso apenas demonstraria a existência de intrusões graniticas de diferentes épocas. $O$ problema parece-me de difícil solução tendo apenas como base a esrtatigrafia" (Teixeira, 1945, p. 124). Notaremos, de passagem, que já Fleury havia tido idêntica percepção: "Les granites indiqués sur la Carte Géologique [de 1899] ne sont pas tous de même âge et cette Carte, ne futce qu'en raison de son échelle, ne peut pas montrer leur véritable allure" (Fleury, 1922b, p. 77).

Em qualquer dos casos, a uniformidade geoquímica (elementos maiores) reconhecida por Cotelo Neiva apontava para uma única intrusão granítica. Esta posição, bem perceptível no mapa geológico 1/1000000 que acompanha a tese de Cotelo Neiva, seria aceite nas Cartas Geológicas de 
Portugal (1/1000000) de 1952 e de 1968.

\section{Lotze e o modelo "hercinotípico" do Maciço Hespérico}

A geologia Maciço Hespérico desde sempre se revelou difícil, devido a factores como a diversidade litológica, a complexidade das estruturas, a variabilidade do metamorfismo, as lacunas do registo fossilífero e, até aos anos 60, a ausência de informação geocronológica.

Deve-se ao geólogo e "hispanófilo" alemão Franz Lotze (discípulo de Stille) o ter pela primeira vez "arrumado a casa": o seu famoso ensaio de 1945 (pouco tempo depois traduzido para castelhano) mostra-nos o Maciço Hespérico) dividido em 6 "zonas" geologicamente distintas e grosseiramente simétricas em relação à zona axial, granítico-metamórfica, Galaico-Castelhana (Fig.1). Respigando da tradução castelhana:

Zona Cantábrica (ZC) - "Una zona marginal del geosinclinal paleozoico de la Meseta".

Zona Astúrico-Leonesa (ZAL) - “(...) desarrollo intenso del Paleozoico inferior".

Zona Galaico-Castelhana (ZGC) - "la zona medular de los variscides de la Meseta".

Zona Luso-Alcúdica (ZLA) - “(...) tiene cierto parecido con la Asturoccidental-Leonesa".

Zona de Ossa-Morena (ZOM) - "la (...) más variada, abigarrada y movida de toda la Meseta Ibérica".

Zona Sul-Portuguesa (ZSP) - "zona marginal del orógeno varisco".

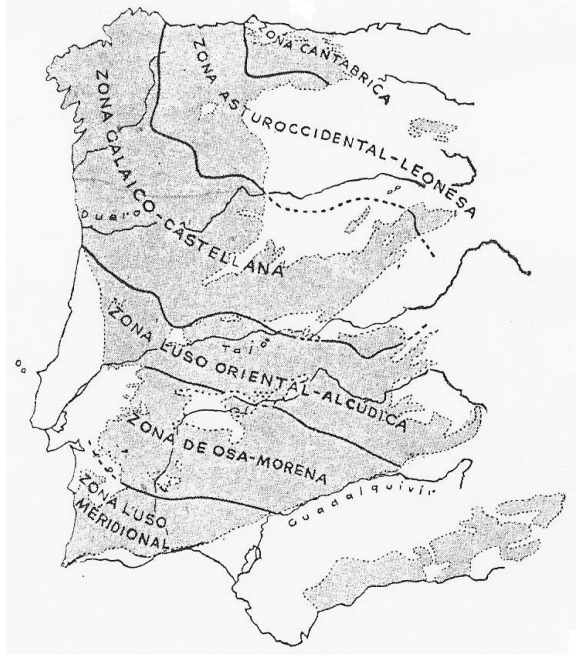

Figura 1. A divisão zonal de Lotze (1945/1950) 
O modelo de Lotze é bastante "hercinotípico", no sentido de essencialmente verticalista, por oposição à cadeia alpina ("alpinotípica"), onde o papel da movimentação horizontal (mantos de carreamento) era de há muito reconhecido; sublinhamos que os termos "hercinotípico" e "alpinotípico" são aqui tomados no sentido que lhes deu H. Zwart (1967). Lotze terá sofrido alguma influência de F. Kossmat, que já em 1927 havia proposto uma divisão zonal idêntica para o Maciço da Boémia (zonas RenoHercínica, Saxo-Turíngica e Moldanúbica). De qualquer modo, a atitude de Lotze é didacticamente interessante, na medida em que basta contemplar um mapa geológico da Península para que nos pareça fácil chegar a um esquema zonal análogo. O problema faz lembrar o "ovo de Colombo": qualquer um podia tê-lo resolvido, mas foi Lotze quem primeiro o fez...

Lotze não avança nada de significativamente novo quanto ao plutonismo da Zona de Ossa-Morena. Já o mesmo se não pode dizer no que diz respeito à Zona Galaico-Castelhana.

\section{A Zona Galaico-Castelhana (ZCA) e os seus granitos.}

Para Lotze, a ZCA é caraterizada por "un poderoso predomínio de los granitos y de las rocas de la serie cristallino-pizarreña" a que se subordinam "elementos menos metamórficos de la serie sedimentaria paleozóica" (Lotze, 1945, p. 154). Os xistos metamórficos são considerados paleozóicos, e os granitos hercínicos. A orogenia varisca estender-se-ia do Devónico inferior ao Estefaniano. Lotze não descarta deformações posteriores, possivelmente saálicas; mas hesita quanto à idade do dobramento principal (bretão? sudético? astúrico?).

A importância dos granitos no espaço galego da ZCA havia sido já realçada por investigadores como I. Parga-Pondal (1935). Lotze reinterpreta-os com base nos trabalhos realizados pelos seus discípulos W. Carlé e P. Schmidt-Thomé. A Carlé tinha sido atribuída a cartografia de um sector da Galiza (Carlé, 1945); Schmidt-Thomé tinha ficado com a cartografia da região de Salamanca-Cáceres (Schmidt-Thomé, 1945). Ambos distinguiam, cartográfica e petrograficamente (Figuras 2 e 3), três grupos cronológicos de granitos (novos, velhos e mais velhos); mas os critérios não eram os mesmos, e a terminologia não deixava de originar alguma confusão. Lotze, com a sua grande experiência e visão sintética, esclarece rapidamente a questão em dois parágrafos e um quadro muito didáctico (Quadro 1):

"Ambos han podido llegar a una división cronológica de los granitos; asi diferencia Carlé los granitos: "más viejo", "viejo" y "joven"; y Schmidt-Thomé: "más viejo", viejo" y "más joven”. Estos no se 
correspondem del todo, sino que de las investigaciones realizadas independientemente por ambos se deduce la existencia de cuatro tipos distintos, que se pueden paralilizar de acuerdo con la representación que se ofrece en el cuadro adujnto.

Con respecto a la situación cronológica de los granitos, parece diferenciarse mucho las concepciones de ambos autores, y, sin embargo, ello depende de los diferentes puntos de vista en que los autores se an colocado: Schmidt-Thomé prestó especial atención a las intrusiones, y, como consecuencia, a sus relaciones con la orogénesis; Carlé, por el contrario, a la solidificación y, por conseguinte, a la textura. De esta manera el cocepto "sinorogénico", para Carlé, no es identico con el "sinorogénico" de Schmidt-Thomé” (Lotze, 1945, p. 155).

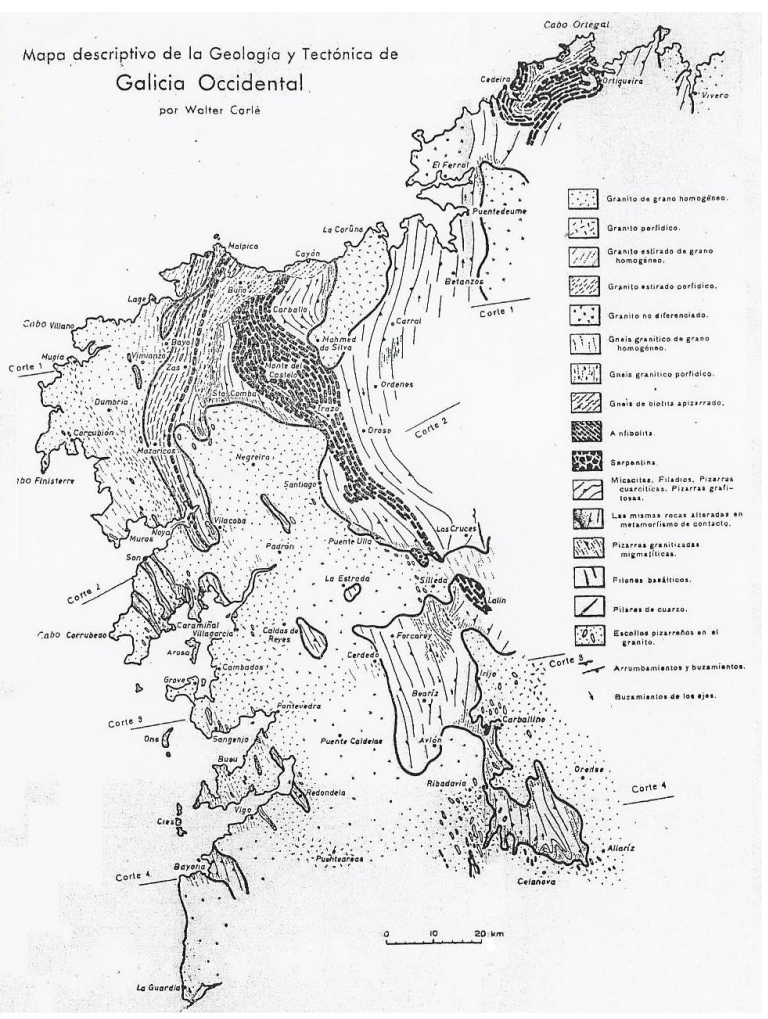

Figura 2. Carta geológica da Galiza Ocidental segundo Carlé (1945/1950). 


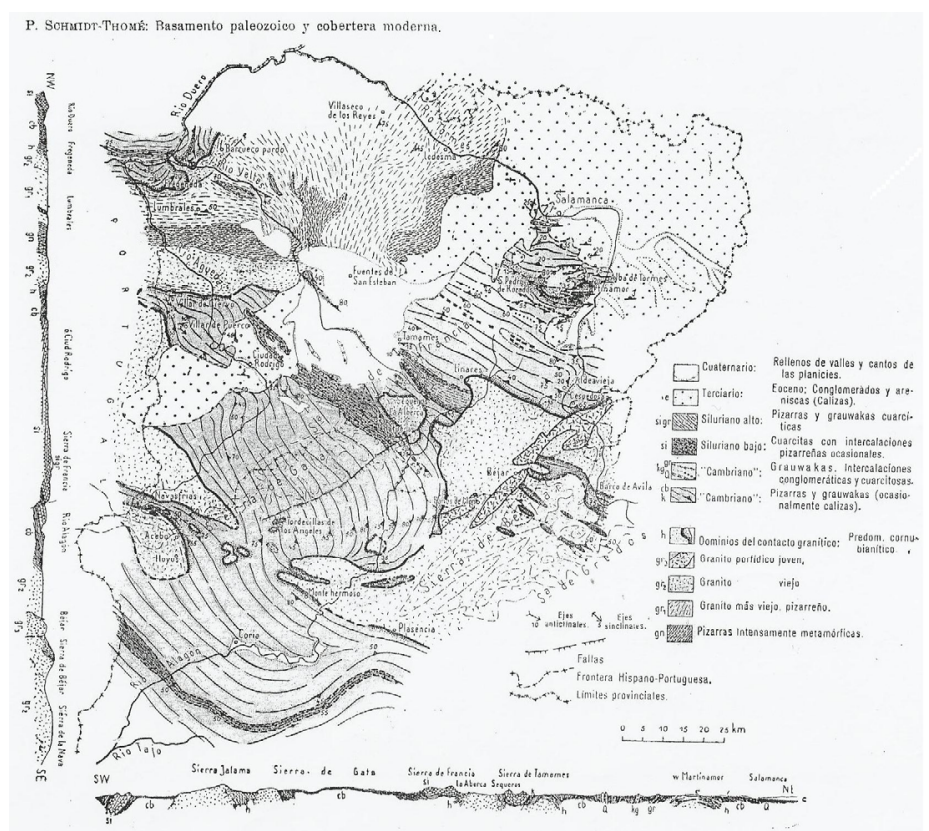

Figura 3. Carta geológica da região de Salamanca Cáceres segundo Schmidt Thomé (1945/1950).

Como seria de prever, Lotze não deixa de fazer uma referência às inevitáveis repercussões na geologia portuguesa:

"La orogénesis de la zona galaico-castellana corresponde, cronológicamente hablando, al intervalo de tiempo comprendido entre el Devoniano inferior y el Estefaniense. Este último sólo se presenta en una localidad, y consiste en un sinclinal bastante largo y estrecho ubicado en la zona de Vallongo. Yace alli discordante con respecto a la estructura antigua, pero experimenó tambián otras deformaciones posteriores (quizás saálicas). Pero si el plegamiemto varisco principal fué bretónico, sudético o astúrico, es tan dificil de decidir como en la zona Astur occidentalleonesa. Por eso tampoco podemos decir a qué intervalo corresponden las intrusiones graniticas; posiblemente, las primeras son ya variscas antiguas, pero las últimas son qizá incluso post-estefanienses. Podría tal vez aclararse esto en Portugal, en Vallongo y al oeste de Castro-Daire" (Lotze, 1945, p. 156). 
Quadro 1. Comparação entre a classificação de Carlé e a de Schmidt-Thomé segundo Lotze.

C UADRO I

\begin{tabular}{|c|c|c|c|c|c|c|}
\hline \multirow[b]{2}{*}{ Tipo } & \multicolumn{2}{|c|}{ Atribución según } & \multirow[b]{2}{*}{ Textura } & \multirow[b]{2}{*}{$\begin{array}{l}\text { Relación } \\
\text { orogenética }\end{array}$} & \multicolumn{2}{|c|}{ Cronología } \\
\hline & CARLÉ & $\begin{array}{l}\text { SchmidT- } \\
\text { THOMÉ }\end{array}$ & & & $\begin{array}{l}\text { De la intru- } \\
\text { sión según } \\
\text { ScHMIDr- } \\
\text { THOMÉ }\end{array}$ & $\begin{array}{c}\text { De la } \\
\text { solidificación } \\
\text { según } \\
\text { CARLÉ }\end{array}$ \\
\hline $\begin{array}{l}\text { IV } \\
\text { III }\end{array}$ & $\begin{array}{l}\text { Granito } \\
\text { joven }\end{array}$ & $\left\{\begin{array}{c}\text { Granito más } \\
\text { joven } \\
\text { Granito vie- } \\
\text { jo }\end{array}\right.$ & Normal & $\begin{array}{l}\text { netamente } \\
\text { discordante }\end{array}$ & $\begin{array}{l}\text { sinorogénico } \\
\text { tardío } \\
\text { sinorogénico } \\
\text { máximo }\end{array}$ & $\begin{array}{l}\text { post orogé- } \\
\text { nico }\end{array}$ \\
\hline & & $\begin{array}{c}\text { Granito } \\
\text { más } \\
\text { viejo }\end{array}$ & $\left\{\begin{array}{c}\text { De estirado } \\
\text { a apizarra- } \\
\text { do. } \\
\text { raramente } \\
\text { Granito } \\
\text { gneísico }\end{array}\right.$ & $\left\{\begin{array}{c}\text { concordan- } \\
\text { te condicin- } \\
\text { nalmente }\end{array}\right.$ & $\begin{array}{l}\text { sinorogénico } \\
\text { del principio }\end{array}$ & - \\
\hline II & $\begin{array}{l}\text { Granito } \\
\text { medio }\end{array}$ & & $\begin{array}{c}\text { Granito gnei- } \\
\text { sico }\end{array}$ & & & $\begin{array}{c}\text { sincer } \\
\text { tario }\end{array}$ \\
\hline I & $\begin{array}{c}\text { Granito } \\
\text { más viejo }\end{array}$ & $\therefore$ & $\underset{\text { tita }}{\text { Gneis de Bio- }}$ & $\begin{array}{l}\text { completa- } \\
\text { mente con- } \\
\text { cordante }\end{array}$ & & $\begin{array}{l}\text { sinorogénico } \\
\text { (¿preorogé- } \\
\text { nico en par- } \\
\text { te?) }\end{array}$ \\
\hline
\end{tabular}

\section{Schneider e o modelo "alpinotípico" do Maciço Hespérico}

Diferentemente do esquema de Lotze (indutivo e fundamentalmente descritivo), o modelo, mais dedutivo e interpretativo, proposto em 1947 por André Schneider tem permanecido a bem dizer ignorado; para tanto terão contribuído 1) o seu conteúdo "avançado" para a época, 2) a escolha do português como língua veiculante e 3) a muito reduzida expansão da revista hospedeira (TÉCNICA, Revista dos Estudantes do IST). Vale a pena meditar um pouco nestas três justificações.

Schneider ("Ex-Assistente dos Profs. P. Ramdohr e H. Stille") veio discretamente para Portugal nos anos 40, escreveu em 1947 dois artigos para a Técnica e um para o Bol. Soc. Geol. Portugal, e sumiu discretamente.

A ideia básica porventura mais audaciosa do esquema de Schneider (Figura 4) consistiu em ver nos Alpes o modelo padrão de todos os orógenos; mas todo o discurso está, aliás, repleto de ideias audaciosas, como parece ser timbre deste investigador: "O progresso das Ciências nunca caminhou pelas vias das grandes demonstrações; - recebeu sempre os seus mais fecundos impulsos pelas grandes hipóteses, que, suscitando o ataque e 
impondo a defesa, revelaram pouco a pouco o tesouro de interpretações de que eram susceptíveis" (Schneider, 1947, p. 523).

Integrando o Maciço Hespérico no segmento da cadeia hercínica a que chamou o "sistema orogénico Ibero-Atlântico", Schneider dividiu-o em duas partes ou "troncos" ("Ibero-Aquitano" a norte, "Lusitano-Açoreano" a sul), separados por um bloco intermediário mais antigo ("inter-país") de cratonização pré-varisca. A sua progressiva compressão entre 2 blocos cratónicos exteriores à cadeia ("ante-países") conduziu ao desenvolvimento de mega estruturas tipicamente alpinas (mantos de carreamento, ou "capas" no português de Schneider). Schneider analisa com algum pormenor no caso do Tronco Lusitano-Açoreano (Figura 4). Este aparece-nos constituído por uma zona autóctone (Zona Subvarisca) e por duas zonas cada vez mais fortemente carreadas sobre aquela (Zona das Plesiocapas e Zona das Telecapas); no interior desta última, os sinclinais ordovícicos ("dobradiças tectónicas", numa feliz expressão) separam 3 capas, respectivamente, de sul para norte, Estremenho-Cordovesa, Beirã-Mariânica e ToledanoCacerenha:

TRONCO IBERO-AQUITANO (não analisado por Schneider)

TRONCO LUSITANO-AÇOREANO

- Zona das Telecapas:

- Capa Toledano-Cacerenha

- Capa Beirã-Mariânica

- Capa Estremenho-Cordovesa

- Zona das Plesiocapas

- Zona Subvarisca

Embora, recorde-se, nos interesse analisar sobretudo o posicionamento dos granitos do Minho e Beiras, parece oportuno referir aqui um aspecto marcante da Zona das Plesiocapas: os seus limites abarcam a Zona de OssaMorena mais uma parte (Faixa Piritosa) da Zona Sul-Portuguesa de Lotze. Curiosamente, a integração da Faixa Piritosa na Zona das Plesiocapas confirma-lhe a unidade na diversidade: 


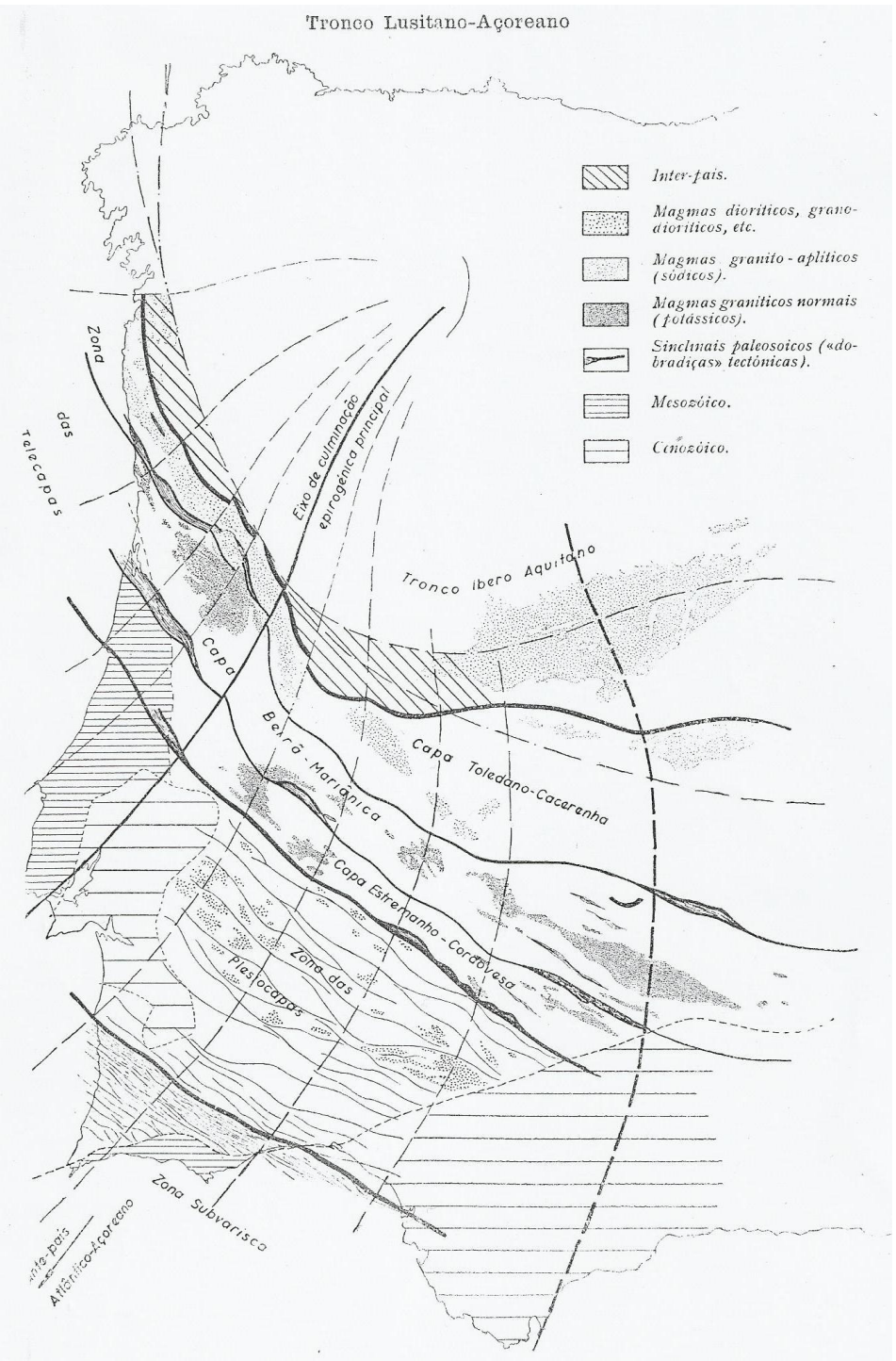

Figura 4. O esquema zonal de Schneider (1947).

"Voltando agora à análise geotectónica (...) reconhecemos com mais facilidade a relação que existe entre a região de alçamento epirogenético pronunciado de Evora, onde a diferenciação das unidades tectónicas é apenas fracamente marcada pela configuração lenticular dos afloramentos graniticos circundados de xistos metamórficos, e a área das séries metamórficas e silúricas da extremidade ocidental da Serra Morena, onde os núcleos graníticos das capas e dobras alpinas ficam abaixo da actual 
superfície de denudação. Tanto a configuração dos afloramentos das raízes graníticas das unidades tectónicas que formam esta zona, como as estreitas faixas do Carbónico intercaladas na vasta área menos levantada dos terrenos dominantemente silúricos, indicam que esta zona geotectónica está ocupada por unidades tectónicas de estilo alpino, mas de amplitude relativamente reduzida, provavelmente do carácter das "plesiocapas de carreamento". Examinando o mapa geológico da região mineira de Rio Tinto e Sevilha, podemos avaliar em 6 até 8 o número destas capas" (Schneider, 1947, p. 534-535).

\section{A Zona das Telecapas e os granitos portugueses}

A zona dos grandes carreamentos ou "telecapas" é dividida em 3 unidades, ligadas pelos sinclinais (ou"dobradiças" tectónicas, na feliz expressão de Schneider) paleozóicos de Anadia - Penacova - S. Mamede Belmez e de Esposende - Valongo - Queiriga - Almadén - Puertollano.

"Destas 3 capas de carreamento de grande amplitude, a unidade inferior, que designaremos por "capa estremenho-cordovesa", ocupa o espaço entre a zona das plesiocapas e a linha Anadia - Penacova - S. Mamede. Nas suas interseç̧ões com os eixos de culminação epirogenética afloram na superfície os núcleos graníticos do Alto Alentejo e da Serra de los Santos (Cordoba). Suas características paleogeográficas, cujo conhecimento nos permite determinar quais dos "klippes" aloctonos que flutuam sobre a zona das plesiocapas (região de Sevilha) derivam desta unidade, indicam, por exemplo, que a bacia de Carbónico produtivo de Santa Susana, constitui um retalho aloctono pertencente à capa estremenho-cordovesa. Entre as analogias mais marcadas, assinalamos o Westefaliano D de Belmez e de Santa Susana, e o Autuniano de Bussaco e da região de Sevilha.

A capa de carreamento que recobre directamente esta unidade inferior da zona das telecapas (...) designaremo-la por "capa beirãmariânica", cujo distintivo estratigráfico mais marcado é o Estefaniano produtivo.

A terceira unidade, a "capa cacerenha-toledana", apresenta um desenvolvimento atrofiado nas regiões ocidentais e tem a sua maior expansão no $S$ e SE dos Montes Toledanos (...). O espraiamento desta unidade sobre as capas "beirã-mariânica" e "estremenho-cordovesa" deve ter atingido uma amplitude particularmente vasta, pois foi nesta região que foram acumuladas as mais espessas camadas paleozóicas e que a sedimentação principiou mais cedo, e terminou também mais tarde" (Schneider, 1947, p. 536-538).

Curiosamente, a problemática dos granitos que afloram na Zona das 
Telecapas torna-se porventura mais compreensível quando se encara o conjunto do Tronco Lusitano-Açoreano (p. 538):

Se voltarmos agora a considerar o conjunto do tronco lusitano açoreano com as várias divisões que acabamos de esboçar, torna-se evidente que cada uma dessas zonas foi dobrada numa fase tectónica distinta. Como foi universalmente comprovado, uma telecapa de carreamento superior, espraia-se sempre sobre um substracto formado pelas capas inferiores, originadas durante fases tectónicas anteriores. Segundo este critério, podemos estabelecer o esquema seguinte da evolução orogenética do tronco lusitano-açoreano (...):

Zona das plesiocapas:

dobramento simultâneo de capas de extensão reduzida, dispostas em festões, durante a fase sudética (?).

Zona das telecapas:

Capa inferior ou "estremenho-cordovesa": fase erzica (conglomerado do Westefaliano D)

Capa média ou "beirã-mariânica": fase astúrica (conglomerado sinorogénico do Estefaniano).

Capa "cacerenha-toledana": fase saálica (por comparação com o tronco ibero-aquitano, região de St. Girons).

Zona subvarisca:

último dobramento na fase saálica (ou palatina?).

Embora reconhecendo a fragilidade deste esquema cronológico, Schneider não hesita em apresentá-lo à discussão pública, e isto por duas razões que nos interessa particularmente referir aqui, visto que ligadas à problemática dos granitos portugueses:

Em primeiro lugar, porque "se baseia sobre o princípio firmemente estabelecido da propagação espacial e temporal dos dobramentos dentro dum tronco orogénico, e desfaz certas controvérsias e mal entendidos sobre a idade dos dobramentos e das intrusões graníticas da Península, satisfazendo todas as opiniões em jogo" (p. 539).

Em segundo lugar, porque,"sem ter estabelecido previamente uma distinção entre as zonas geotectónicas e esclarecido a sequência cronológica dos processos pliomagmáticos respectivos, nunca poderemos obter uma ideia clara sobre a diferenciação dos magmas-troncos durante a orogenia, sobre a evolução química destes magma sem relação com a deslocação sucessiva dos fenómenos intrusivos duma zona geotectónica para outra, etc..., problemas de importância capital para a análise das zonas metalogenéticas" (p. 539).

Enfim, um aspecto suplementar, com fortes incidências 
metalogénicas, tem que ver com os granitos tardios:

"Outro fenómeno tectónico típico para estas áreas [andares geotectónicos elevados] é o "diapirismo magmático" originado pelos granitos saálicos. O magma-tronco saálico, de acidez particularmente elevada e de tipo potássico, irrompe nas capas ante-saálicas com violência, formando batólitos de extensão relativamente reduzida e de configuração nitidamente discordante com as estruturas alpinas. Em casos frequentes, $o$ magma saálico penetra nos granitos astúricos, ou ainda anteriores, originando auréolas de metasomatismo e fenómenos de hibridização granítica. A metalogénese tungsteno-estanifera está quase exclusivamente relacionada com estas intrusões "diapíricas", e segundo o nível atingido por estas intrusões, temos tipos estruturais diferentes dos jazigos de estanho e volfrâmio. Particularmente característicos são os filões subhorizontais, de disposição chamada "lit-par-lit", que se observam na maioria dos grandes jazigos de volframite (Panasqueira, Borralha, Arouca, Cassayo, etc...), cuja formação está estreitamente relacionada com o diaparismo magmático exercido pelos granitos saálicos nestas áreas" (p. 539).

A comparação entre os modelos de Lotze e de Schneider é um exercício deveras interessante e digno de ser praticado. Caricaturando um pouco as coisas, pode dizer-se que as zonas de Lotze se encontram justapostas (lado a lado) e as de Schneider (parcialmente) sobrepostas. O modelo de Lotze faz apelo a movimentos (sobretudo) verticais da crosta, o de Schneider a movimentos (sobretudo) horizontais (mas não exactamente no sentido wegeneriano, ou seja, não implicando necessariamente continentes à deriva). As zonas de um raramente coincidem (se é que coincidem) com as zonas do outro. Elaborados no quadro da Teoria Geossinclinal, teoria refinada pelo mestre comum, Stille, e então de certo modo paradigmática, ambos constituem preciosas fontes de reflexão, num tempo em que as atenções se concentram na Tectónica de Placas.

\section{Conclusão}

Como é sabido, o conhecimento dos granitos portugueses sofre um fortíssimo impulso em meados dos anos 50, com os trabalhos realizados na Beira Alta pela Escola de Amesterdão, nomeadamente a síntese preliminar de Westerveld (1955) e a tese seminal de Schermerhorn (1956). Trabalho idêntico seria realizado na Galiza nos anos 60 (pelas Escolas de Leiden e de Montpellier), culminando com a tese, também seminal, do francês Capdevila (1969). É o início da "explosão moderna", onde se integra uma nova, entusiasta e cada vez mais numerosa falange de granitólogos 
portugueses e espanhóis. As ferramentas disponíveis enriquecem-se e diversificam-se, sejam elas materiais (geofísica, geoquímica oligoelementar e isotópica, detecção remota...) ou conceptual (tectónica de placas, modelação matemática...). É costume, pelo menos em Portugal, enraizar todo este edifício moderno nos trabalhos da Escola de Amesterdão. Mas seria injusto não reconhecer que os alicerces foram construídos, com trabalho, inteligência e imaginação, na década de 40 .

É com grande prazer que dedicamos este breve exercício histórico ao colega e amigo Manuel Maria Godinho. Ele foi o introdutor de uma nova e rigorosa forma de tratar a problemática dos granitos portugueses (Godinho, 1980). E fez escola, na Universidade de Coimbra, com a criação de um pequeno e belo grupo de discípulos. Mas ele próprio foi também ilustre discípulo de um dos pioneiros da década de 40, o Prof. Cotelo Neiva.

\section{Bibliografia}

Capdevila, R. (1969) - Le métamorphisme régional progressif et les granites dans le segment hercynien de Galice Nord Orientale (NW de l'Espagne). Tese Univ. Montpellier; $430 \mathrm{p}$.

Carlé, W. (1945) - Ergebnisse geologischer Untersuchungen im Grundgebirge von Galicien (Nordwest Spanien). Geotekt. Forsch; 6 (trad. esp. por J.M. Rios, in Publ. Estranj. Geol. España, 1950; V, 61-91).

Cotelo Neiva, J. M. (1944a) - Manifestações de actividade magmática em Portugal. Bol. Soc. Geol. Portugal; 4(1-2), 41-60.

Cotelo Neiva, J. M. (1944b) - Jazigos portugueses de cassiterite e de volframite. Tese Univ. Porto e Comunic. Serv. Geol. Portugal; 25, 1-251.

Cotelo Neiva, J. M. (2009) - A fundação da Sociedade Geológica de Portugal e os seus primeiros sócios. Bol. Soc. Geol. Portugal; 35, 11-12.

Fleury, E. (1922a) - O que pode ler-se na Carta Geológica de Portugal. J. Sci. Nat.; I, 1-2, 7-12.

Fleury, E. (1922b) - Les plissements hercyniens en Portugal. Comunic. Serv. Geol. Portugal; 13, 6583.

Godinho, M. M. (1980) - O plutonito do Caramulo. Tese Univ. Coimbra e Publ. MLMG Univ. Coimbra; $269 \mathrm{p}$.

Lotze, F. (1950) - Zur Gliederung der Varisziden der Iberischen Meseta. Geotekt. Forsch, 1945; 6 (trad. esp. por J.M. Rios, in Publ. estranj. geol. España; V, 149-166).

Schermerhorn, L. J. G. (1956) - Igneous, metamorphic and ore geology of the Castro Daire - S. Pedro do Sul - Sátão area (Northern Portugal). Tese Univ. Amesterdão e Comunic. Serv. Geol. Portugal; 37, $617 \mathrm{p}$.

Schmidt-Thomé, P. (1945) - Paläozoiches Grundgebirge und junges Deckgebirge in Westlichen Zentralspanien (Provinz Salamanca und Cáceres). Geotekt. Forsch; 6: 37.77 (trad. esp. por J.M. Rios, in Publ. estranj. geol. España, 1950; V, 93-146).

Schneider, A. (1947) - Prospecção mineira e zonas geotectónicas na metalogénese ibérica. II Parte As zonas geotectónicas da Península Ibérica. TECNICA, Revista dos Estudantes do IST, Lisboa; $176,522-540$.

Teixeira, C. (1945) - O Antracolítico continental português (Estratigrafia-Tectónica). Tese Univ. Porto e Bol. Soc. Geol. Portugal; 5(1-2), 1-139.

Teixeira, C. (1954) - Notas sobre geologia de Portugal. O sistema Permo-Carbónico. Ed. Autor, 55 p. 
Westerveld, J. (1955) - Roches eruptives, gîtes métallifères et métamorphisme entre Mangualde et le Douro dans le nord du Portugal. Bol. Soc. Geol. Portugal; 12, 101-127.

Zwart, H. (1967) - The duality of orogenic belts. Geol. En Mijnb.; 46e(8), 283-309. 